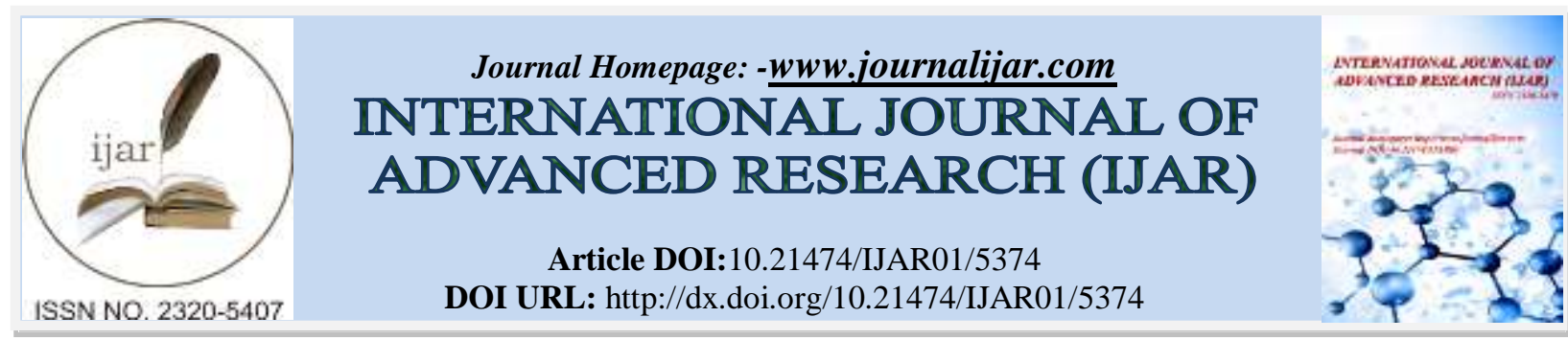

RESEARCH ARTICLE

\title{
REINTEGRATION AND REHABILITATION OF SEX TRAFFICKED NEPALESE WOMEN: A STUDY OF THEIR EXPERIENCES ON RETURN AND PROGRAM ACTIVITIES OF A REHABILITATION NGO.
}

\footnotetext{
${ }^{1}$ Sudha Sen Malla, ${ }^{2}$ Dipendra Raj Pandeya, ${ }^{3}$ Mahesh Bhusal, ${ }^{4}$ Meenakshi Gurung and ${ }^{2}$ Prachi Rayamajhi.

1. Department of Community Medicine, Nepalese Army Institute of Health Sciences-College of Medicine.

2. Department of Biochemistry, Nepalese Army Institute of Health Sciences-College of Medicine.

3. Nepalese Army Institute of Health Sciences-College of Medical Polytechnic.

4. Department of Dental Surgery, Nepalese Army Institute of Health Sciences-College of Medicine.
}

\section{Manuscript History}

Received: 09 July 2017

Final Accepted: 11 August 2017

Published: September 2017

Key words:-

HIV, AIDS, NGO, STI, Sex trafficked women, UNAIDS.

\section{Manuscript Info}

\begin{abstract}
The trafficking of women from poor, developing countries to other countries for the purpose of sexual trade is a global problem which is associated with immeasurable human suffering and tragedy. Not only does sex trafficking cause intolerable degradation and suffering to young girls and women, it is associated with significant mental and physical health risks, such as depression and HIV/AIDS. The aims at increasing our understanding of the context of sex trafficking and to describe program activities of Maiti Nepal, a non-governmental organization, in Kathmandu, Nepal to reintegrate repatriated or returned sex trafficked women, to describe the impact of these activities on the lives of the repatriated women.

The methodology consisted primarily of in-depth interviews with returned women undergoing rehabilitation at Maiti Nepal, supplemented by focus group discussions with returned women and Maiti Nepal staff.

Responses from the participants overwhelmingly indicated that Maiti Nepal's program activities had been instrumental in increasing their selfconfidence, bringing about healing of their deep emotional trauma, and their eventual rehabilitation as functioning and productive citizens.

This preliminary study was largely exploratory and small-scale, and there is a need for long-term follow-up of repatriated sex trafficked survivors to more accurately assess the impact and evaluate appropriateness of each program activity such as individual counseling, family counseling, skill training etc. and to develop better strategies. Long-term follow-up is also required to assess impact of care and support. The findings of this study should be useful to the government to formulate more effective policies and programs.
\end{abstract}

Copy Right, IJAR, 2017,. All rights reserved.

\section{Introduction:-}

Human trafficking is a major international health and human rights concern ${ }^{1}$, which disproportionately targets females. Nepal, a poor country in the South Asian region, is particularly vulnerable to this problem. Sex trafficking causes intolerable degradation and suffering to young girls and women and increases risks to their physical and mental health, as well as increases their vulnerability to HIV/AIDS. The carpet and garment factories

Corresponding Author:-Sudha Sen Malla.

Address:-Department of Community Medicine, Nepalese Army Institute of Health Sciences-College of 658 
of the Kathmandu valley are intermediate points from where the girls are trafficked to Indian brothels. Most of the girls and women are sold by their own parents, relatives of their husband, or friends of the family ${ }^{2}$. About $7 \%$ reported that they were forcibly abducted from Nepal and taken across the porous Nepal-Indian border and sold to brothel owners in India ${ }^{1}$. It is reported that an estimated $50 \%$ of the sex workers in Mumbai's Kamathipura red light district alone are Nepalese ${ }^{3}$.

Low socio-economic status of women, hardship, lack of awareness, gender discrimination, lack of employment opportunity, domestic violence, and extreme poverty have increased the vulnerability of Nepalese women/girls to trafficking and sexual abuse ${ }^{4}$. In addition, lack of enforcement of existing laws and the lack of political commitment to the issue of women trafficking have led to increased trafficking of women in Nepal.

The medical and social needs of women/girls who were once sex trafficked to India are huge. These women need medical services, emotional and counseling support as well as they also needs privacy and confidentiality ${ }^{5}$. There are national and international Non-Governmental Organizations (NGOs) that are actively involved in the rehabilitation of repatriated sex trafficked girls/women. They provide returnees with shelter, food, psychological treatment, medical treatment, legal support, as well as skill-development programs ${ }^{6}$.

Besides forced prostitution, sex trafficking also poses significant individual and public health consequences ${ }^{7}$. Among the most significant potential health consequences of sex trafficking is the increased risk of HIV infection. Once released from sex work, women and girls often face societal stigma and are shunned from all sectors of society. Rehabilitation and reintegration are problematic when society continues to ostracise the returnees ${ }^{8}$.

Only a few NGOs provide shelter to these women and girls at their rehabilitation centers which focus on repatriation and reintegration of these survivors with the society ${ }^{4}$. Maiti Nepal is an NGO dedicated to protecting the rights of women and girls ${ }^{9}$. It is also committed to bringing about changes in the lives of women and young girls who have been trafficked and sexually exploited. It has three regional offices located in the Eastern, Central, and Western parts of the country. Not only does it work to prevent trafficking, it is also involved in protecting, rescuing, and rehabilitating trafficking survivors. Among its activities, an important component is to do with raising public awareness regarding women trafficking, HIV infection and the consequences associated with it ${ }^{9}$.

Maiti Nepal has a Rehabilitation Home for returned trafficked women ${ }^{9}$. The main activities of the Rehabilitation Home are to provide shelter, arrangement for education, provide vocational training, income generating skills, facilitate medical check-ups and treatment, conduct counseling and psychotherapy sessions, file cases against accused criminals, identify parents and encourage survivors to set up their own enterprises and become selfreliant ${ }^{9}$.This study aims at increasing our understanding of the context of sex traffing and to describe program activities undertaken by Maiti Nepal, a non-governmental organization, to rehabilitate sex trafficked women after their return from India.

\section{Material and Methods:-}

This was a descriptive, retrospective study design. It used qualitative research techniques consisting of semistructured interviews and a FGD to elicit the respondents' experiences and describe program activities and their impact on the respondents.

The field research took one and half month with initial 4 weeks spent on data collection, followed by preliminary data analysis to develop the hypothesis, and a final data collection period.

Participating NGO for the study was Maiti Nepal which is a local organization providing shelter and care to repatriated Nepalese sex trafficked women since 1993. It is part of a network of NGOs across South Asia active in trafficking prevention and intervention services for repatriated sex trafficked women.

A questionnaire guide was used to facilitate FGD with both returned trafficked women and Maiti Nepal staffs. The textual data were analyzed using thematic content analysis, which involved identifying issues and experiences from individual interviews. These themes were then analyzed to develop a comprehensive picture of their experiences and also the program activities at Maiti Nepal. 


\begin{abstract}
Results:-
Demographic data of traffic survivors:-

In all, 10 trafficked survivors at Maiti Nepal were interviewed. The following socio-demographic characteristics were noted among them.
\end{abstract}

All the survivors were very young at the time they were trafficked, with more than half of the women being below 18 years. While at the time of their enrolment into Maiti Nepal, about half were in their early 20 s. More than $50 \%$ of the respondents belonged to the lower castes and had never been to school, although they were able to write or sign their names. All the respondents reported a very low family income that averaged less than a dollar a day. Furthermore, half of them were married at the time of being trafficked; majority of them trafficked by their own husband.

\title{
Experience of traffic survivors while being repatriated to Nepal:-
}

Six of the ten respondents had been trafficked to Mumbai in India indicating that this was the most common trafficking destination. Other destinations in India were Gujarat, Assam, Calcutta, Delhi, Surat, and Kamatipur. As mentioned earlier, half of the respondents had been sold to the Indian brothels by their husbands. Thus, they experienced severe feelings of betrayal, with most expressing that they could never trust anyone in their life again. As one respondent said, "I felt betrayed. I was sold to a brothel owner in India by a person whom I trusted very much. I was not able to trust people anymore (after this). I felt lonely and that my life was shattered."

In the brothels, the respondents were virtual prisoners of the brothel owners or pimps, with no easy ways for escape. Three respondents were rescued with the help of the Rescue Foundation which is an NGO in Mumbai working to help trafficked victims. Another three were rescued during raids on brothels by Indian police who then handed them over to the Rescue Foundation in Mumbai. One respondent escaped with the help of a customer, one was rescued with the help of social workers in India, and two managed to escape on their own at great personal risk.

The story of one respondent graphically illustrates the horrific nature of the ordeal faced by these women when being trafficked. This survivor recounted how she and her child were first trafficked from her home to India by a group of traffickers who included her husband. En route they sold one of her kidneys before selling her off to a brothel owner. While escaping from the brothel she had a miscarriage and almost bled to death. She was helped by a male social worker who eventually managed to get her back to Nepal. On arriving in Nepal, she was rejected by her family, whereupon she went to live with her sister. After she had recovered somewhat from her ordeal, she along with her sister went to Maiti Nepal for help. She said, "I felt lonely, and devastated. When I arrived in Nepal I was in a bad shape. After I came to Nepal from India, I could hardly imagine that I would be able to work and make a living for myself and my son. Because I was very sick, I didn't know where to go. I stayed with my sister as my parents did not want to accept me back. People in the community also taunted me. A policewoman in Kathmandu told me about Maiti Nepal and its work with traffic survivors. Therefore, I came to them for help. " This unfortunate woman did receive some justice. Maiti Nepal helped her to successfully file a case against her traffickers including her husband, with the result that all have now been convicted and imprisoned.

None of the respondents had heard of Maiti Nepal before, and the first time most of them heard of it was at the Rescue Foundation, where they were informed about the work of Maiti Nepal in Kathmandu, and reassured that they would be taken good care there.

At the time of their arrival in Maiti Nepal, almost all were traumatized and emotionally and physically devastated, with a few expressing no desire to continue living. Their reception by their own community and family after arrival in Nepal was often unwelcoming and cold. Only four survivors said that they were welcomed and treated well by their family. Even these women decided not to live in their former communities in order to save their families from ostracisation by people in the community. Four survivors said that their families did not welcome them at all, while two survivors preferred not to contact their families after arriving in Maiti Nepal, as they feared the likely hate and discrimination they would face from their neighbours and other people in the community.

\section{Program activities of Maiti Nepal:-}

Maiti Nepal was established with a vision and aim to prevent women trafficking in Nepal and to help traffic survivors to rehabilitate and reintegrate into their communities. It works in coordination with the Indian police and Indian organization in order to rescue Nepalese traffic victims from Indian brothels and repatriate them to Nepal 
safely. Maiti Nepal's programs for returned trafficked women include three Prevention Homes, two Rehabilitation Homes, a Hospice, community outreach programs as well as community Awareness Programmes in different parts of the country.

\section{Rehabilitation:-}

Traffic survivors arriving at Maiti Nepal are given safe shelter at its rehabilitation homes and transit homes. Immediately after arriving at the Rehabilitation Home in Kathmandu, they receive a medical check-up and treatment, and then counseling. Traffic survivors are often not accepted by their families and community, so they need to be given shelter and support. Thus, Maiti Nepal provides them with the basic needs of shelter, food, medical care and clothing. In addition, Maiti Nepal provides them with vocational and professional trainings to enable to become self-sustaining, and also helps with finding jobs within or outside the organization.

\section{Counseling:-}

At the time of entry into Maiti Nepal, the trafficked survivors are physically and psychologically scarred. Counseling is provided not only to the survivor women but also to their families to help them to accept them in their families and provide the love and support they need after such an ordeal.

\section{Health Services:- \\ Hospice:-}

The Maiti Nepal Hospice on the outskirts of Kathmandu in Gokarna provides shelters for trafficked survivors (and their children) who are seriously ill with HIV/AIDS. It provides shelter, round the clock medical services, balanced diet, clothing, and holistic care. Anti-retroviral therapy is provided to all HIV/AIDS positive women, as well as affected children, thus reducing morbidity and mortality rate even though it does not cure the disease.

There were 19 survivors and 26 children at the Hospice in 2007. The Hospice also provides shelter and treatment for survivors suffering from psychiatric disturbances as a result of their experiences during trafficking and at the Indian brothels.

\section{Health clinic:-}

There is a clinic, Sonja Jeevan Kendra, at the main shelter and head quarter of Maiti Nepal in Kathmandu. The clinic provides care, support and regular medical services to all the trafficked survivors and their children.

\section{Reintegration of survivors:-}

Maiti Nepal facilitates harmonious re-union of traffic survivors with their families and communities. The women and their families are provided with information about women's rights and trafficking, and health issues such as HIV/AIDS, and counseled about the eventual reintegration of their daughter into the family and community. Even after the women are reintegrated with their families, Maiti Nepal follows up the situation of the women and provides counseling if needed.

\section{Skills Development Training:-}

After the women are stable physically and emotionally and after two weeks of advocacy, Maiti Nepal staffs select survivors for skills development training depending on their skills and interests. The training has helped women to become economically independent and start working once they leave Maiti Nepal, and thus contributes to their effective reintegration within their communities.

\section{Education:-}

All survivors arriving at Maiti Nepal receive non-formal education, as most of them are illiterate. Maiti Nepal provides formal education to traffic survivors who want to take up education. They are enrolled in the school 'Teresa Academy' which is run by Maiti Nepal at the shelter. The school also provides education to children of the survivors. Educating traffic survivors helps them to gain self esteem as well as to become self sustainable.

\section{Filing Court cases against traffickers:-}

Maiti Nepal is helping traffic survivors taking shelter at Maiti Nepal to file cases against their traffickers in the court. The legal section at Maiti Nepal follows up each case until the court gives its decision. The women are provided free legal assistance and support to identify their traffickers and take legal action. 


\section{Employment opportunities:-}

Some survivors were employed in various areas within Maiti Nepal such as its Head Office, Shelter, clinic, and Teresa Academy School etc. as helpers, receptionists, cook, caretaker, and security guard and some were employed at the workshop owned by Maiti Nepal which specializes in handmade products. For others, Maiti Nepal provides micro-credit loans so that they can start their own small business and make a living.

\section{Awareness raising programs:-}

Maiti Nepal has been giving training to survivors on promoting awareness against women/human trafficking and HIV/AIDS. Such training helps to empower survivors and enables them to communicate effectively with people in the communities on issues of women's rights, women trafficking, HIV/AIDS.

\section{Problems faced by Maiti Nepal:-}

The main problems faced by Maiti Nepal include the difficulties encountered in locating the families of trafficked survivors. Maiti Nepal staff also face security threats from traffickers. Human trafficking is a well organized criminal activity in Nepal. When traffickers are identified and captured, Maiti Nepal staffs sometimes receive pressure from politicians to free the criminals. Indeed, on occasions, criminals had to be freed because of tremendous pressures from vested quarters.

\section{Impact of program activities on survivors:-}

Trafficked survivors who participated in the study all commented on the range of program activities at Maiti Nepal that was having a positive impact on their lives. In particular, they mentioned about the skills training they received as being crucial to making them more confident about making a living for themselves and their children on their reentry into society. They were all appreciative of the shelter, food, and medical care they had received at Maiti Nepal. They were also appreciative of the counseling they received at Maiti Nepal as it was crucial in helping them to share and ease their pain and sorrow, and becoming more positive about their future, even if they had HIV/AIDS. Almost all the survivors were also grateful for the regular medical checkups and anti-retroviral therapy that helped them to lead an almost normal life.

These findings reveal that women trafficked for sexual exploitation are at very high risk of HIV infection. Findings from the qualitative data analysis indicated that sex trafficked women need to be supported and rehabilitated. Maiti Nepal operates a wide-ranging and comprehensive set of activities to care for and rehabilitate these women. All the program activities implemented by Maiti Nepal are found to have a positive impact on these women.

\section{Discussion:-}

As the responses from our study participants indicated, women who were trafficked to India and could subsequently return to Nepal often suffer from psychological distress. The symptoms include sleeplessness, suicidal tendencies, and anger. These women can get frustrated with their lives and develop feelings of mistrust and hatred towards men. After their repatriation, most of these women are worried about how their family would react to their return and whether they would be accepted back into the family. In that respect, counseling by Maiti Nepal appeared to have helped these unfortunate women, with their morale and self confidence being considerably boosted. Women with HIV/AIDS need even more support and counseling because of the double stigma of being a sex trafficked woman and HIV/AIDS. Such psychosocial counseling has been found to be very effective in dealing with the symptoms of extreme loneliness, nightmares, helplessness and/or suicidal ideation that are found among trafficked women who had been repatriated from Indian brothels ${ }^{\mathbf{1 0}}$. Most of the women interviewed did not want to go back to their family as they did not want to become an economic or social burden. Some families also did not want their daughters back because of the fear of social expulsion from the community. Therefore, organizations working with such women must first consider assessing whether or not it would be in the woman's best interests to be reintegrated with her family.

In South Asian countries, stigma and discrimination are associated with trafficked women and HIV/AIDS, in which gender also appears to play an important role ${ }^{11}$. The rates of discrimination and violence against traffic survivors and HIV infected women are very high in Nepal which is also one of the root causes of re-trafficking of these women. Normally, HIV infected women in Nepal are forced out of their husband's home or parents' homes and denied their right to inheritance ${ }^{11}$. Infection with HIV further aggravates the stigma and discrimination faced by these women ${ }^{11}$. 
There is little information about what South Asian countries are doing to reduce stigma and discrimination of traffic survivors. However, in the researcher's experience, the government and NGOs in Nepal appear to be trying to raise public awareness through the media and distribution of Information Education Communication (IEC) materials about the evils of human trafficking and the needs of survivors. . But these efforts suffer from a lack of coordination between the different agencies involved in such programmes. Reduction of stigma and discrimination associated with traffic survivors and with HIV/AIDS would encourage traffic survivors to come forward and get themselves tested and restart their lives.India has the largest number of people living with HIV infection and has the highest rate of human trafficking both internally and internationally in South Asian region ${ }^{12}$. India is both a transit country and destination for human (women) trafficking for purposes of sex trade. The country which contributes the largest number of women for sex trafficking in India is Nepal ${ }^{13}$. According to a study by UNICEF, around 200,000 Nepalese girls and women are working in the Indian sex industry. Many of them are younger than 16 years of age ${ }^{14}$, an age group that is known to be particularly vulnerable to HIV infection.

The study revealed a wide and comprehensive range of rehabilitative activities carried out by Maiti Nepal, which can be upheld as an exemplar of a holistic and integrated program for the provision of basic medical care, shelter, and rehabilitation to repatriated sex-trafficked women not only in Nepal but also in other developing countries. In terms of care and support, Maiti Nepal provides advocacy, clinical care, psychological support, livelihood opportunities, child care, and nutritional support. It is also offering vocational training, job placement assistance and basic education to repatriated trafficked survivors. In addition, it implements community awareness programs and border surveillance programs to identify and intercept trafficking. To our knowledge, there are no other agencies in Nepal that provides the same breadth and range of services for these unfortunate women. Maiti Nepal's activities are dependent on external funding which needs to be sourced on an annual or periodic basis. Similar programs and activities throughout South Asia suffer from the same problems of underfunding or uncertain funding. Greater advocacy and publicity about the role these agencies play in rehabilitating the lives of sex trafficked women are crucially important in order to garner further and increased support and funding for their programs.

Responses from the participants in our study overwhelmingly indicate that Maiti Nepal's program activities have been instrumental in increasing their self-confidence, bringing about healing of their deep emotional trauma, and their eventual rehabilitation as functioning and productive citizens. Our study highlighted the critical need to strengthen and expand these types of efforts in order to reduce women trafficking as well as to improve the lives of these traffic survivors. Major NGOs in India, such as the Rescue Foundation, and in Nepal such as Maiti Nepal and $\mathrm{ABC} / \mathrm{Nepal}$, are working as partners in the rescue of trafficked women and care of traffic survivors ${ }^{15}$. Furthermore, support and care of traffic survivors with HIV infection is not only a human right obligation, but it is also an important preventive activity. Preventive activities without care and support for traffic survivors are likely to be less credible and effective ${ }^{11}$.

Most of the IEC (Information, Education, and communication) materials distributed by NGOs in Nepal have little information on safe migration ${ }^{16}$. Furthermore, the messages written in these materials say that "girls return, their youth destroyed, most come back with AIDS and die", "Because of trafficking, AIDS in Nepal is increasing daily." Such messages lead to stigmatization of traffic survivors who are trying to reintegrate with their families and the communities. A re-evaluation of these messages and development of new messages will help to reduce stigma among returning survivors which will in turn help survivors to reintegrate better within the community ${ }^{16}$. In addition, migrating women and girls should receive information on safe migration so that they are less likely to become victims of sex trafficking. Maiti Nepal has been successful to some extent in raising public awareness through the media and distribution of Information Education Communication (IEC) materials about the evils of human trafficking and the needs and rights of traffic survivors. They have also tried to raise public awareness regarding HIV/AIDS with a view to reducing the stigma and discrimination associated with traffic survivors and with HIV/AIDS. However, Maiti needs to be supported by many other partners and stakeholders in society, as the problem of stigma and discrimination in Nepal is huge and there is a lack of cooperation and coordination among the relevant sectors.

Counseling is an integral part of the care and rehabilitation of repatriated trafficked women. Maiti Nepal has full time trained counselors who adopt an interactive and empathetic approach with the survivors which enables them to work through their experiences and reach decisions about their futures ${ }^{16}$. NGOs also provide family counseling encouraging the families to accept their daughters. However, most of the NGOs do not perform follow-ups after the women are reintegrated with their families or in their communities. In this respect, Maiti Nepal does a very good job 
of conducting follow-up visits ${ }^{16}$. NGOs working in this field provide skills training traditional and non-traditional training to survivors before returning to their communities. Care and support provided by Maiti Nepal for survivors include: long-term residential care, medical care, skills training, job placement, supporting more independent living, arranging marriages. Maiti Nepal has also encouraged a group of survivors to set up their own NGO, KishoriSamuha, which works on trafficking and women's rights in Kathmandu. KishoriSamuha organizes community awareness programs on safe migration and human trafficking. Maiti Nepal believes that economic improvement is the basis of women's empowerment. Therefore, it also provides seed money to survivors to start their livelihood. Such measures for their future are still at a rudimentary stage in Nepal due to the lack of capacity and resources among NGOs ${ }^{16}$ and the government.

Maiti Nepal provides medical treatment for HIV positive survivors and has also opened a centre where traffic survivors with HIV/AIDS are provided with holistic care as well as given opportunities to participate in activities such as agriculture, animal husbandry, and kitchen gardens. HIV positive survivors reported being very happy with the care and support they were receiving at Maiti Nepal. Unfortunately, government agencies and NGOs are often constrained in their ability and power to prosecute traffickers. Maiti Nepal actively works to prosecute traffickers and assist trafficking survivors to present their case in the court with financial and moral support during presence at the hearings. However, their work is sometimes hampered by corruption in the judiciary and insensitivity by government prosecutors towards the needs of survivors ${ }^{16}$. The National Plan of Action on trafficking calls for counseling and medical care of traffic survivors, legal assistance, use of survivors as peer educators, and enabling environment for continuous health and counseling programs, community mobilization, advocacy, and maintenance of privacy. The National Plan of Action and proposed anti-trafficking reform bill have high emphasis for establishment for rehabilitation centers for repatriated traffic survivors. However, they have been proved to be ineffective since both the approaches do not specify clearly the desired outcomes and duration of stay at such centers.

\section{Conclusion:-}

Nepal is now considered to be severely affected by women/human trafficking and HIV/AIDS. It is very difficult to obtain clear data on the number of repatriated sex trafficked Nepalese women due to lack of resources. Reintegration of survivors into the family and community may become difficult due to various reasons. Traffic survivors may find it difficult to readjust in their families and communities due to traditional values and norms. Nongovernmental organizations and government should ensure that traffic survivors with or without HIV receive medical treatment and receive access to services without discrimination. It is better to involve traffic survivors in advocacy, policy development, and interventions to control the women trafficking, spread of HIV/AIDS, improve care and support to repatriated traffic survivors.

Intervention programs should be implemented by government and NGOs to reduce economic, social, and gender inequalities in the communities which will help to reduce women trafficking and HIV/AIDS in the communities. Gender-based discrimination and violence against women in all South Asian countries including Nepal should be reduced to create a society free of human (women) trafficking and HIV/AIDS. Because, these are the main driving forces of women trafficking and HIV/AIDS among women.

HIV/AIDS and women trafficking have common root causes such as gender inequity, violence against women, poverty, lack of employment, and lack of proper information. They also call for similar responses such as reduction of gender-based violence, reduction of stigma and discrimination, providing adequate information, and increasing employment opportunities.

\section{Disclosure:-}

The authors declared no conflicts of interest. 


\section{References:-}

1. Maheshwari, Ayonija, Yale Medicine Thesis Digital Library, Health Status and Health Needs of Women and Girls Trafficked to Mumbai, India for Sex Work. Available from http://ymtdl.med.yale.edu/theses/available/etd06282006-114419/ (Accessed on September 2, 2007)

2. O'Dea, P, 1993, Gender Exploitation and Violence: The Market in Women, Girls and Sex in Nepal, UNICEF, Nepal.

3. F. Luckoo, M. Tzvetkova, Combating Trafficking in Persons: A Directory of Organizations, Anti-Trafficking Program, Change, London, 2002.

4. Hennick M, Simkhada P. Sex trafficking in Nepal: context and process. Opportunities and choices working paper. No. 11. April 2004

5. Suvedi, BK (1997), 'Ethics in relation to HIV/AIDS in Nepalese context', Journal of Medical Association, No.7

6. PratimaPoudel, Jenny Carryer, Girl-trafficking, HIV/AIDS, and the position of women in Nepal, Gender and Development, Volume 8, No. 2, July 2000, page 74-79.

7. United Nations. Protocol to Prevent, Suppress, and Punish Trafficking in Persons, Especially Women and Children, Supplementing the United Nations Convention Against Transnational Organized Crime. 2000.

8. UjolSherchan, Mountain Children of Nepal: A Lost Generation? World Mountain Symposium, 2001.

9. Annual Report, 2006, Empowering Against Exploitation, Maiti Nepal, 2006.

10. Mark J.D. Jordans, Wietse A. Tol, Bhogendra Sharma, Mark van Ommeren, Training psychosocial counselling in Nepal: Content review of a specialized training program,Intervention: the International Journal of Mental Health, Psychosocial Work and Counselling in Areas of Armed Conflict, 2003, 1, 18-35.

11. National Consultation on HIV and Anti-Trafficking: Exploring Engendered Linkages and Strengthening Care and Support, 03-04 AUGUST 2006, HDRN - USAID www.hdrn.org (assessed onSeptember 20, 2008).

12. Human Trafficking and HIV: Exploring vulnerabilities and responses in South Asia, Embargoed till 22 August 2007, UNDP

13. Jay G. Silverman, Michele R. Decker, Jhumka Gupta, AyonijaMaheshwari, Brian M. Willis, Anita Raj, HIV Prevalence and Predictors of Infection in Sex-Trafficked Nepalese Girls and Women, JAMA. 2007; 298(5):536542

14. The Asia Foundation, Trafficking in Nepal: An Overview. www.asiafoundation.org (assessed on July 10, 2008)

15. Jay G. Silverman et al., Sex Trafficking and HIV within South Asia: Research, Challenges, and Next Steps, JAIDS, 2006.

16. The Asia Foundation, Prevention of Trafficking and the Care and Support of Trafficked Persons: In the Context of an Emerging HIV/AIDS Epidemic in Nepal, February 2001, www.asiafoundation.org (assessed on September 20, 2008) 